\title{
Encephalopathy Related to Ivermectin Treatment of Onchocerciasis in Loa loa Endemic Areas: Operational Considerations
}

\author{
Takougang Innocent ${ }^{1}$ and Muteba Daniel ${ }^{2}$ \\ ${ }^{1}$ Foundation for Health research \& Development, Yaoundé, \\ ${ }^{2}$ National Programme for Onchocerciasis Control, Kinshasa, \\ ${ }^{1}$ Cameroon \\ ${ }^{2}$ The Democratic Republic of Congo
}

\section{Introduction}

Human onchocerciasis is a public health problem and an obstacle to socioeconomic development in endemic countries of Africa, Arabian Peninsula and South America (WHO, 1995). The community-directed treatment with ivermectin (CDTI) is the main strategy adopted by the African Programme for Onchocerciasis control (APOC). Severe adverse events with encephalopathy (SAEs) have been associated with mass treatment with ivermectin (Mectizan) in areas where Loa loa and onchocerciasis are co-endemic (Duke, 2003; Twum-Danso, 2003). This has caused wide spread concern on the sustainability of CDTI (Amazigo et al., 2002; Addiss et al., 2003). The most important risk encountered in distributing ivermectin for the control of onchocerciasis in areas where Loa loa is co-endemic is the development of an encephalopathic syndrome. The pathogenesis of Loa loa encephalopathy is not fully understood, but the primary determinant is the level of Loa loa microfilaraemia (Gardon et al., 1997; Boussinesq et al., 1998; Gardon et al., 1999; Boussinesq et al., 2001) and the inflammatory response to the dying worms (McGarry et al., 2003).

Post ivermectin treatment encephalopathies with fatal outcome have repeatedly been the subject of clinical and operational investigations. Investigations have targeted aspects of implementing mass drug administration, monitoring and referral of early signs of SAE, improved clinical management in the communities and health facilities.Research for primary prevention have also witnessed the development of operational tools, aimed at identifying high risk communities, using in the communities and health NormalizedDifference Vegetation Index (NDVI) and rapid assessment methods (Diggle et al., 2007). For the later purpose, RAPLOA is used to identify communities at risk of SAEs. The objective of the present chapter is to provide an updated review of gathered evidence on the pathophysiology of Loa loa mediated encephalopathy and the existing methods for its prevention and case management at the community level. 


\section{Epidemiology}

Onchocerciasis, also known as river blindness, is caused by a filarial nematode, Onchocerca volvulus. The adult worms lives in subcutaneous nodules within surface muscles, mainly around the pericostal and the iliac crest.

There are two mains subtypes of Onchocerca volvulus, namely the forest and savanah. In the savanal infections, the nodules are mainly located on the upper part of the body, including the trunk, upper limbs and head. Ocular involvement is frequent. In the forest infections, nodules are found primarily on the lower limbs and iliac crest. Cutaneous alterations are the main manifestations of the disase.

The worm is transmitted through the bite of female blackflies of the genus Simulium, which bite during the day. The fly breeds in rapidly flowing rivers and streams.

Onchocerciasis is endemic in most countries in sub-saharan Africa. Isolated endemic foci are also present in the Arabian Peninsula (Yemen) and in the Americas (Brazil, Colombia, Ecuador, Guatemala, southern Mexico, and Venezuela). An estimated 17 million people are infected worldwide.

The distribution of the disease has been substantially narrowed with the successful implementation of the Onchocerciasis Control Programme in West Africa (OPC) and the African Programme for Onchocerciasis Control (APOC). OPC used aerial spray of insecticides for the control of onchocerciasis fly vector from 1974 to 2000 when the programme closed down, after reaching its goal. APOC began its activities in 1995. Its main strategy is the annual or biannual distribution of ivermectin, a safe and effective drug that was licensed for human use in 1987. APOC is a partnership involving international donors, the private sector including pharmaceutical companies, Non-governmental Organizations and communities. The delineation of roles and responsibilities within the partnership has been the subject of extended literature and consultative statutory meetings regularly hold to monitor progress towards the control and elimination of the disease. Unfortunately, progress in the control of onchocerciasis in APOC countries met with difficulties as the programme progressed towards central Africa where the level of endemicity of Loa loa is highest. Loa loa is a filarial worm that inhabits the subcutaneous tissue of humans. The disease is transmitted from one host to the other through the bite of the Chrysops fly. The adult breeds in marshy forested habitats. In areas that are co-endemic for both onchocerciasis and loiasis, the mass administration of ivermectin for treatment of onchocerciasis sometimes leads to the occurrence of Severe Adverse Events (SAE) consisting of a potentially lethal encephalopathy.

Short-term travelers to endemic areas are at low risk for this infection. Travelers who visit endemic areas for extended periods of time (generally $>3$ months) and live or work near black fly habitats are at risk for Loa loa infections.

Infection with $O$. volvulus results in skin lesions, including a highly pruritic, papular dermatitis; subcutaneous nodules; lymphadenitis. Ocular lesions occur in endemic countries and can progress to visual loss and blindness. Historically, the term river blindness was coined from the blindness that occurred along streams that were onchocerciasis transmission sites. Symptoms in travelers are primarily dermatologic and may occur months to years after departure from endemic areas. Immigrants from endemic areas may present with skin or ocular disease. 
Onchocerciasis is diagnosed by finding the microfilariae in punch biopsy, adult worms in histologic sections of excised nodules or characteristic eye lesions. Serologic testing is most useful for detecting infection in specific groups, such as expatriates with a brief exposure history, when microfilariae are not identifiable. It is equally expected that serological tests and molecular markers will get into wide use as interventions move towards disease elimination goals.

Ivermectin (150-200 $\mu \mathrm{g} / \mathrm{kg}$ orally, once or twice per year) is the drug of choice for onchocerciasis. Repeated annual or semiannual doses may be required. The drug kills the microfilariae but not the adult worms, which can live for 15-17 years. Antibiotic trials with doxycycline (100 mg orally per day) directed against Wolbachia, an endosymbiont of $O$. volvulus, have demonstrated a decrease in onchocercal microfiladermia with 6 weeks of therapy. Therefore, some experts recommend treating patients with 1 dose of ivermectin followed by 6 weeks of doxycycline. Several health workers however advocated against the wide use of antibiotics in communities as it could foster specific or cross another constrain is the problematic compliance with the numerous doses treatment regimen.

Subcutaneous nodules can be excised if their anatomic location allows it to be done safely.

No vaccine or drug to prevent Onchocerca infection is available. Protective measures include avoiding blackfly habitats and the use of personal protection measures against biting insects.

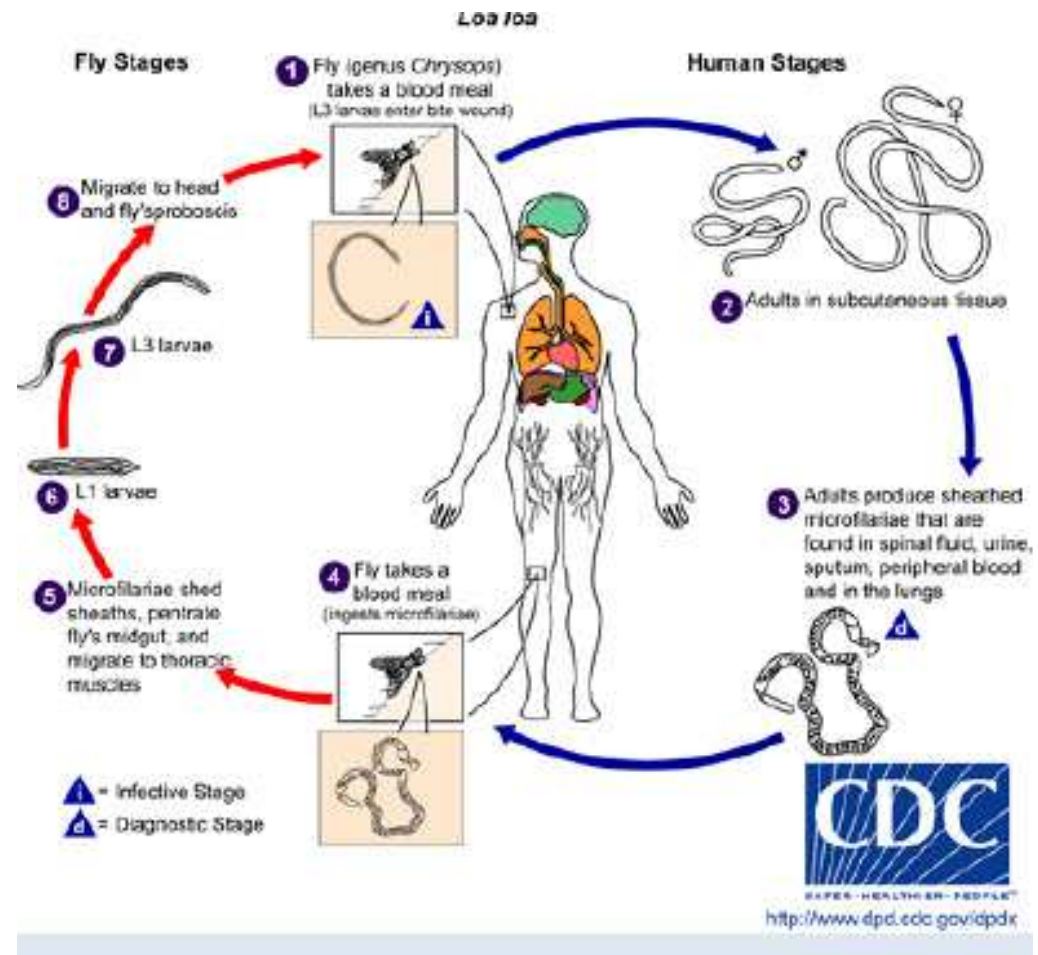

Fig. 1. Life cycle of the Loa loa parasite, involving the human host and the Chrysops vector. Reprinted from the CDC webpage. 


\section{Particularities of the health infrastructure in onchocerciasis and loiasis endemic areas}

Populations most affected by onchocerciasis and loiasis live in remote areas of endemic countries where they are poor and underserved by the health system. In fact, despite the Alma Ata Declaration on Primary Health Care (PHC) of 1978 - a system envisaged for improving access to health interventions - equity and access to essential health services remain sub-optimal in sub-Saharan Africa, especially in rural areas. The international community have recognized the potential of PHC (WHO, 2008). There are attempts to its revitalization and PHC has been placed high on the agenda of several international fora (African Review of the Implementation of PHC in Ouagadougou).

Recent efforts by the World Health Organisation (WHO, 2006) emphasized that a significant proportion of the national health budget should focus on interventions linked to the MDGs, targeting those most in need. Unfortunately, African health systems continue to be weak, with fragmented interventions. Health services lack effective mechanisms for making any real impact on the high burden of infectious diseases. Health systems in onchocerciasis endemic countries (mainly in Africa) lack sustainable frameworks to involve partners from other development sectors. However, a functioning health system is the backbone to support sustainable interventions. Community participation enhances the affordability of health interventions compared to conventional, vertical programmes, as recurrent costs become more affordable (Gish, 1992). In order to enhance community participation and engagement in the delivery of health services, many African countries have set up dialogue structures to facilitate communication between the health system and communities. These dialogue structures help bring promotion, prevention and cure together in a safe, effective, socially acceptable and productive way to the population. Its comprehensiveness, integration and continuity, make the dialogue structure a point of entry into the community to build an enduring relationship of trust between people, their health-care providers and the health system. Some of these structures have survived, but others have collapsed. Their poor conception and the exclusion of communities in their inception are some of the reasons of the failure. One of the cornerstones of PHC is working in partnerships. The partnerships that make the greatest impact in the rural population are those that are grounded at the community level. However, the mechanism for bringing together partners to improve their collaboration at this level remains problematic. The Community Directed Treatment with Ivermectin (CDTI), a process in which the community has the responsibility for the organization and delivery of treatment has been adopted by the African Programme for Onchocerciasis Control (APOC) as its strategy to control of onchocerciasis (Brieger et al., 2002). CDTI promotes active community participation in decision making as a means of improving access to the drug, promoting a sense of responsibility and appropriation. It enhances ownership and empowerment of communities (Amazigo et al., 1998). CDTI is a stimulus for developing primary health care in areas with difficult access to formal health services (Hopkins, 1998; Richards et al., 2004). Field trials revealed the efficiency of communities to deliver multiple interventions of various degrees of complexity, thus strengthening the link between communities and the health system (WHO, 2008). Comprehensive revitalization of primary healthcare holds the potential to insure equity in access to health services. Community engagement and involvement in the planning, delivery and monitoring of health interventions, strengthens the interactions between health services and the communities and enhance needs-based and demand-driven provision of 
services which in turn strengthens PHC delivery schemes (WHO, 2008). The lack of a legal framework and normative orientation also plague optimal community participation and stakeholders' engagement. Community monitoring and referral of SAE cases is crucial in the management of onchocerciasis control programme in areas that are at risk of Loa loa mediated encephalopathy.

\section{Pathophysiology of Loa loa mediated encephalopathy}

Loa loa encephalopathy is related to the worm burden, especially the hypermicrofilaremia. Though its mechanism is not sufficiently understood, it is known that Ivermectine (Mectizan)®, in addition to being an effective drug against the microfilariae of Onchocerca volvulus (the causative agent of onchocerciasis), is also effective against $L$. loa microfilariae, the rapid killing of which has been associated with this encephalopathy. Encephalopathy may also be linked with higher permeability of brain capillaries as they react to a higher load of worm antigen released after massive destruction of Loa loa microfilaria in response to ivermectin administration.

The obstruction of brain capillaries by paralyzed microfilariae lead to local ischemic reactions, increased pressure within the capillaries, rupture of the affected vessels and hemorrhagic suffusion. The hemorrhage equally occurs on the conjunctiva mucosa or on the palpebral area. The last manifestation has been used as a prognostic sign of encephalopathic involvement.

\section{Identification of individuals and communities at risk of encephalopathy}

\subsection{Primary prevention of encephalopathy}

The reactions of Loa loa to onchocerciasis drugs date back from the use of Diethyl Carbamazine (DEC=Notezine) when severe adverse reactions with encephalopathy were reported. Ivermectin was known as a safe drug for the mass treatment of onchocerciasis until the 1999 when several cases of SAEs occurred as distribution moved to the forest areas of Cameroon and Nigeria, that are breeding environments for Chrysops flies, the vectors of Loa loa.

The high number of cases that occurred in Cameroon lead administrative authorities and APOC to stop distribution until clarifications were provided, the causes elucidated and preventive measures laid out. The World Health Organisation special programme for Research and Training in Tropical Diseases (TDR), together with a team of African scientist lead the development of RAPLOA, a rapid assessment method based on the history of migration of the adult Loa loa worm through the conjunctiva. Primary prevention equally makes use of community knowledge of Loa loa, which is an indicator of the level of endemicity. RAPLOA has been used to map the risk of Loa loa encephalopathy, in priority areas for onchocerciasis lymphatic filariasis within the framework of Neglected Tropical Diseases (NTD) control. (Figure 2)

The delivery of RAPLOA entails the administration of a community and individual questionnaires. The RAPLOA community questionnaire helps in getting an onerall view the community experience and endemicity of Loa loa. Simple names for eye worm are often associated with high prevalence, while complex and composite names are associated to lower prevalences (Table 1). 


\begin{tabular}{|c|c|c|c|}
\hline $\begin{array}{l}\text { Language / } \\
\text { ethnic group }\end{array}$ & Villages & Vernacular name & $\begin{array}{l}\text { meaning } \\
\text { (etymology) }\end{array}$ \\
\hline Baya & $\begin{array}{l}\text { Bedobo, Mbelibina, } \\
\text { Bengue Tiko, Mbile, } \\
\text { Belikoungou }\end{array}$ & $\begin{array}{l}\text { Yolo } l i \\
\text { yolo=worm } l i=\text { eye }\end{array}$ & Worm of the eye \\
\hline Baya & $\begin{array}{l}\text { Mbelebina, Camp } \\
\text { SODEPA, Bambouti, } \\
\text { Garga Sarali, Ndanga } \\
\text { Gadima, Dabole, }\end{array}$ & $\begin{array}{l}\text { Peng } l i \\
\text { peng=worm } l i=\text { eye }\end{array}$ & Worm of the eye \\
\hline Foulbe & $\begin{array}{l}\text { Camp SODEPA, } \\
\text { Ndanga Gadima, } \\
\text { Mbile, Belikoungou }\end{array}$ & $\begin{array}{l}\text { Guildé guité } \\
\text { guildé=worm } \\
\text { guité=eye }\end{array}$ & Worm of the eye \\
\hline Kako & Djal, Djassi & Ntoro & Worm of the eye \\
\hline Kako & $\begin{array}{l}\text { Nyamsambo, Kamba } \\
\text { Mieri, Ngoura, } \\
\text { Ngoulmekong, Letta, } \\
\text { Gbabele, Pouyanga, } \\
\text { Gaba Letta, } \\
\text { Kpangalakonga, Banda, } \\
\text { Mbouye, Dem } 2\end{array}$ & $\begin{array}{l}\text { Kon missi } \\
\text { kon=sickness } \\
\text { missi=eye }\end{array}$ & Eye sickness \\
\hline Maka & Bouam, Baktala & $\begin{array}{l}d a \\
\text { biep } \\
\text { Naki }\end{array}$ & Worm of the eye \\
\hline Mbimou & Mbiali & Ntoli & worm of the eye \\
\hline Mezime & $\begin{array}{l}\text { Kagnol I, Bokendja, } \\
\text { Kapang, Djampiel }\end{array}$ & Djol & Worm of the eye \\
\hline Mvongmvon & Djemba & Dol & Worm of the eye \\
\hline Pol & Grand Pol & $\begin{array}{l}\text { kon mich } \\
\text { kon=worm } \\
\text { mich=eye }\end{array}$ & Worm of the eye \\
\hline
\end{tabular}

Table 1. Vernacular names of eye worm in villages of Eastern Cameroon

Several other conditions have been reported to favor encephalopathy in loasis areas and confound with the determinants of SAE. Among these are the consumption of alcoholic beverages, especially the traditional, non standard drinks that contain mixtures of alcohols, some of which may be neurotoxic such as methanol.

Operational guidelines have been provided by the Technical Consultative Committee (TCC) of APOC on the implementation of ivermectin mass distribution in areas that are co-endemic for onchocerciasis and loiasis. Within this scheme, blanked treatment is not recommended and a distribution by axis is advocated based the capabilities of the human resources for health, infrastructure and logistic for the early detection, referral and management of cases. 
Encephalopathy Related to Ivermectin Treatment

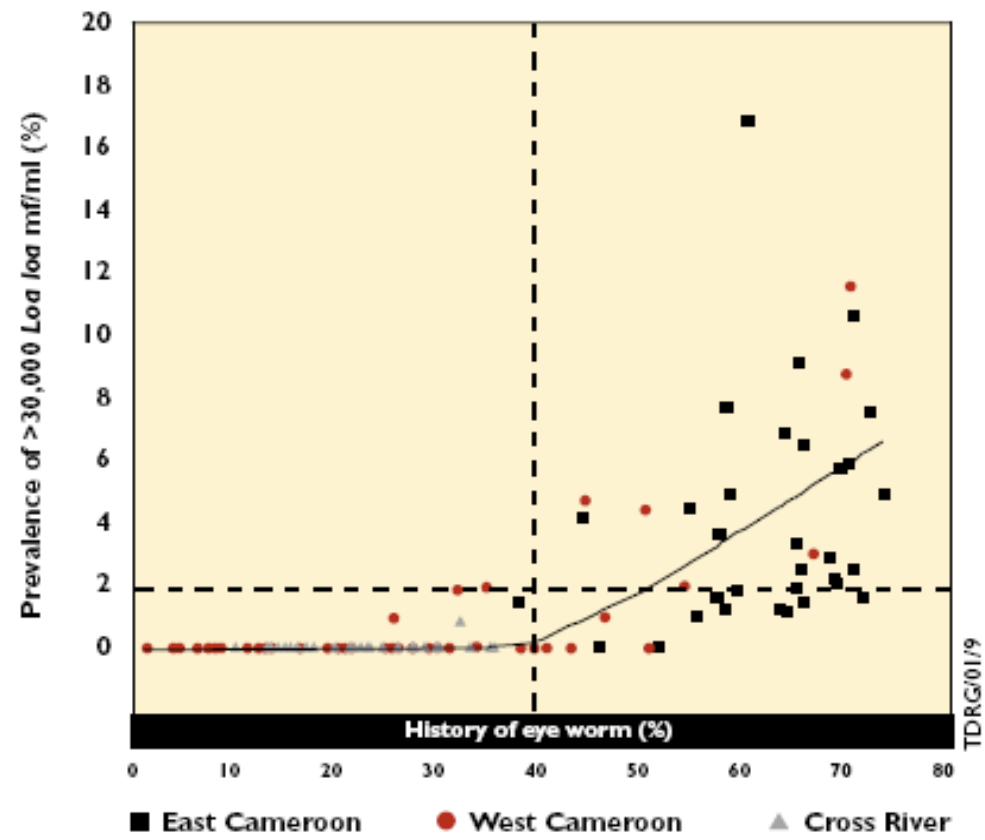

Fig. 2. Relationship between the prevalence of very high microfilarial loads $(>30.000 \mathrm{mf} / \mathrm{ml})$ and RAP based on the history of eye worm (From TDR. Guidelines for the Rapid Assessment of Loa loa).

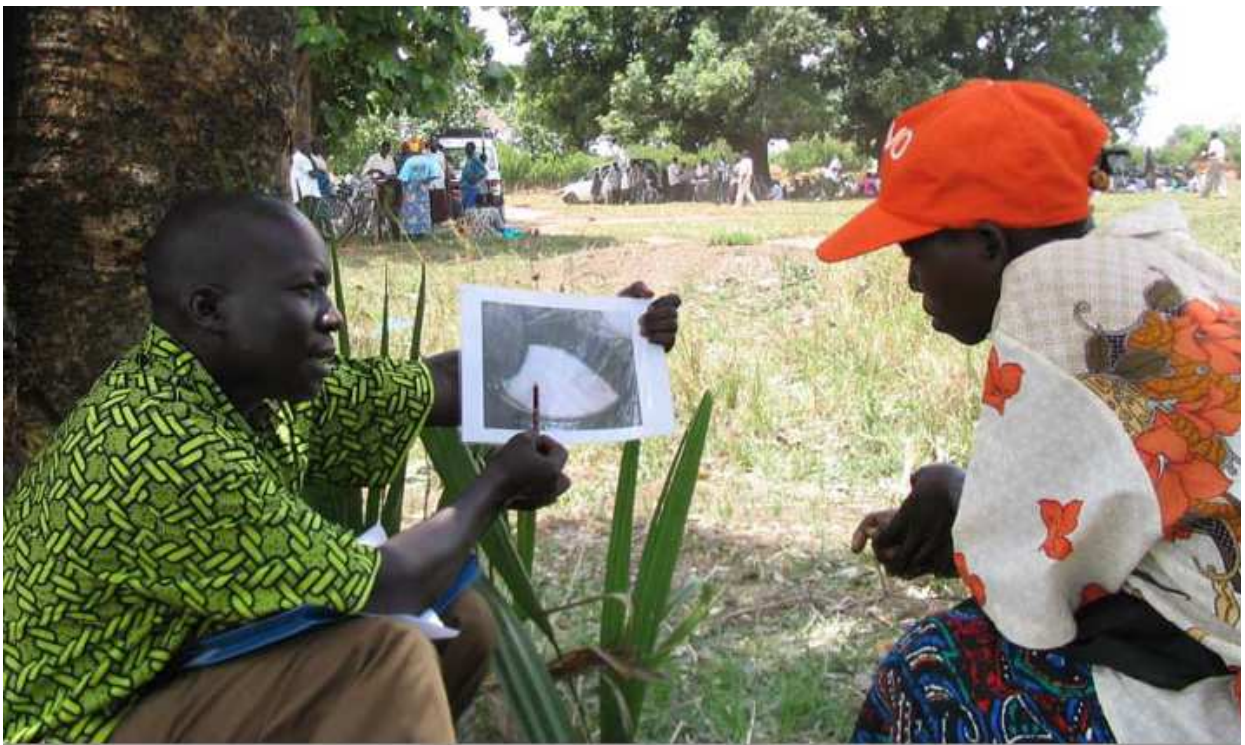

Fig. 3. Delivery of the RAPLOA individual questionnaire to assess the risk of SAE at the community level, using the illustrated eye worm in Southern Sudan (Photo Dr Takougang) 


\subsection{Secondary prevention of encephalopathy}

Not all cases of SAE may be avoided through primary prevention. Thus, early identification and referral of cases of encephalopathy is of paramount importance. Early detection offers improved prognosis. In this regard, ataxia, sub-palpebral hemorrhage have been successfully used, two-three days after treatment, to identify and manage cases of SAEs which would have otherwise developed encephalopathy.

Many lessons have been learned for improved clinical management of cases of encephalopathy in hospital settings. This has lead to improved survival and reduction in mortality among cases.

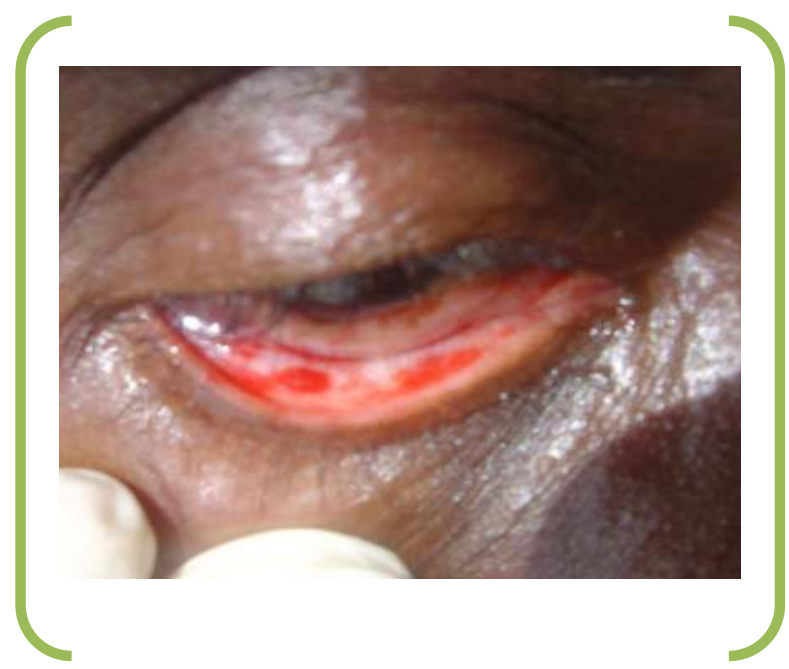

Fig. 4. Sub-palpebral hemorrhage in a case of SAE in Cameroon (Photo Dr J. Kamgno).

\subsection{Tertiary prevention of encephalopathy}

The literature on the tertiary prevention of encephalopathy is scanty. Apart from clinical data that indicate measures to prevent bed sores, there is very little data on the disabilities that occur following SAE and encephalopathy. The sequelae and their impact on the patient's productivity and quality of life needs to be assessed.

\section{Clinical and paraclinical features of Loa loa mediated encephalopathy}

Post onchocerciasis treatment encephalopathy occurs in people with very high levels of $L$. loa $[>30,000$ microfilariae/milliliter blood $(\mathrm{mf} / \mathrm{ml})]$ following treatment with Mectizan ${ }^{\circledR}$. The patient often presents with fever $\left(39-40^{\circ} \mathrm{C}\right)$, head ache and ataxia. Signs of central nervous system involvement may follow. Such signs include confusion, omnibulation, lethargy, ataxia, anal and urinary incontinence. Unattented, the patient progresses into into coma. 


\section{Differential diagnosis}

Encephalopathy is a brain disease, damage or malfunction. Encephalopathy presents in a broad spectrum of symptoms that range from mild, such as memory loss or subtle personality changes to dementia, seizures, coma and death. Encaphalopathy on the early is often accompanied by physical manifestations such as poor coordination of limb movements (NINDS, 2011).

A wide range of causes may lead to encephalopathy may be infectious (bacteria, viruses, parasites), anoxia (lack of oxygen to the brain), alcohol consumption, liver failure, kidney failure, metabolic diseases, brain tumors, toxic chemicals, alterations in pressure in the brain, and poor nutrition of nerve cells.

Despite the numerous and varied causes of encephalopathy, an altered mental state is usually present. It may be subtle and develop slowly over years or rather rapidly (for example, brain anoxia leading to coma or death in a few minutes). Often, symptoms such as poor judgement or poor coordination of movements are reported. The severity and type of symptoms are related to the underlying cause. Alcohol-induced encephalopathy can result in involuntary hand tremors, while severe anoxia may result in coma with no movement.

The diagnosis of encephalopathy is usually done by clinical tests done during the physical examination (mental status tests, memory tests, coordination tests) that document an altered mental state. Findings on clinical tests either diagnose or presumptively diagnose encephalopathy. Usually, a diagnosis is made when the altered mental state accompanies another primary condition such as chronic liver disease, kidney failure or anoxia.

Many practitioners view encephalopathy as a complication that occurs following a primary underlying health problem. The frame work for the diagnosis and management of cases of encephalopathy includes Complete blood count; search for underlying infections, assessment of blood pressure (high or low blood pressure); blood levels of electrolytes, glucose, lactate, ammonia, oxygen, and liver enzyme levels; drug use or toxin levels (alcohol, cocaine, amphetamines, ..); ceresbrospinal fluid analyses; kidney function (creatinine)

Other diagnostic tools may be useful, but are not often present in Loa loa endemic settings. These include Computer Tomography (CT) and Magnetic Resonance Imaging (MRI) scans to assess brain swelling, anatomical abnormalities or infections; Doppler ultrasound to assess blood flow to tissues, encephalogram to assess brain wave patterns.

In the case of Loa loa encephalopathies, microfilariae are sought in a standardized finger prick thick blood smear. The presence of such is indicative of the involvement of Loa loa in the genesis of encephalopathy. However, under the endemic conditions, infections agents such as Neisseria meningitidis, the cause of bacterial meningitis, Toxoplasma gondii, and malaria must be ruled out. Cerebral malaria is a likely co-factor in the occurrence of encephalopathy. Clinical orientation, experience, of the treating physician, the specific symptoms and history of the patient are of paramount importance in the early detection and management of cases. 


\section{Case reports}

Several cases of Loa loa encephalophathy occur each year in the DRC. During the 2009 Mectizan distribution, the country reported the highest number in the history of participating in activities. Below are a selected number of cases to point out clinical presentation and management.

\section{Case Report \#1}

Patient WB, aged 33 years old lived in the city of Abuzi in the Abuzi health Zone in the Equateur Province (The Democratic Republic of Congo). He swallowed 3 tablets of ivermectin on the 10/11/2009. He was $149 \mathrm{~cm}$ tall and weighed $52 \mathrm{~kg}$. His general state was good before he swallowed ivermectin tablets. He had no history of alcohol consumption 24 hours before or after ivermectin treatment. He presented with fever, altered behavior and coma on 11/11 2009, one day after he swallowed the tablets. He was transferred to the Abuzi reference hospital on the 12/11/2009 and was admitted on same day. At admission, the patient had urinary incontinence. His blood pressure and temperature were within the normal limits. Coma, stage 2 was diagnosed by the attending physician.

Emmergency biomedical investigations revealed a microfilaremia of 2520 Loa loa $\mathrm{mf} / \mathrm{ml}$ from of a thick blood film. The analysis of a concurrent thin blood smear revealed Plasmodium falciparum trophozoites.

The diagnosis made by the attending physician was that of cerebral malaria with encephalopathy post ivermectin treatment.

The treatment administered included:

Intravenous drips of quinine in 5\% glucose, Ringer lactate serum or physiological saline solutions.

Antibiotics (Ampicilline, Direct intravenous injection) were equally administered was provided for bed sores as appropriate.

Three days after admission, the patient developed bed sores that were unhealed on $14 / 12 / 2009$, when he was discharged. On discharge, the patient still experienced difficulties walking.

\section{Case report \#2:}

Patient F., aged 28 years was from the village of Bukarawa, Loko Health Zone in the Equateur Province of the Democratic Republic of Congo. She was admitted in the Loko Health Zone Reference Hospital. At admission, the patient blood pressure was 180/120 $\mathrm{mmHg}$, the Glasgow score was estimated at 5 (coma stage 2) ; Temperature was $39^{\circ} \mathrm{C}$.

For her $146 \mathrm{~cm}$ height, the patient was reported to have taken 3 tablets of Mectizan $100 \mathrm{~g}$ on 06 December 2009. The general health status was good prior to the absorption of Mectizan tablets. On 06 December 2009, about 6 hours after absorption, the patient developed intense fever, altered behaviour and fainted. It was in this state that she was transferred to the reference hospital on 08 December 2009. Upon investigations with siblings the patient had not taken any alcoholic drink over the past 24 hours. On admission, the patient had bed sores on the lower part of the lower back, around the sacrum. 
The presumptive diagnosis was that of a Loa loa encephalopathy related to ivermectin, associated to cerebral malaria or meningitis.

Biomedical evaluation of a thick blood film revealed Loa loa microfilariae $(620 \mathrm{mf} / \mathrm{ml})$. The glycemia was $186 \mathrm{mg} / \mathrm{dl}$, that decreased to $111 \mathrm{mg} / \mathrm{dl}$ on the second day. White blood cell count was $9550 / \mathrm{mm} 3$, and the sedimentation coefficient (VS) $91 \mathrm{~mm} / \mathrm{h}$.

The following treatment was administered: Intravenous administration of Quinine in 5\% Glucose serum for 3 days. Glucose and Ringer Lactate were alternatively use as solutes.

The anti-hypertensive drug Adalate $2 \times 10 \mathrm{mg}$ was administered through a nasogastric gavage; Lasilix (Lasix) $40 \mathrm{mg}$ was administered intravenously.

The antipyretic drug Dipyrone was used in an intramuscular injection of 4X1g / day.

For hyperleucocytopenia, an association of Ampicilline and Chloramphénicol was administred through direct intravenous injection $3 \times 1 \mathrm{~g} /$ day.

To alleviate bedsores, a nursing protocole for patient mobility was set. Topical antiseptics were used to cleanse the wound of the lower back.

The treatment was followed for 5 days. However, the feverish state persisted, reaching $40,5^{\circ} \mathrm{C}$ on day 5. Diastolic blood pressure went from 120 down to $100 \mathrm{~mm} \mathrm{Hg}$. The systolic Pressure decreased from 190 to $160 \mathrm{mmHg}$ despite the treatment administered.

The patient died on day 5 .

\section{Management of cases of Loa loa mediated encephalopathy}

Like all life threatening conditions, Loa loa encephalopathy requires prompt medical and nursing care to provide supportive treatment and prevent nosocomial infections. With competent and timely medical care, patients usually recover.

The main features of case management include the monitoring of vital signs, nutrition and nursing care.

Vital signs of importance are blood pressure, pulse, body temperature and respiratory frequency. Nasogastric intubation may be useful in maintaining hydrolytic and nutrients intake for energy support.

Rehydration using Ringer Lactate, physiological solution, hypertonic glucose may be used depending on the patient preexisting health status. Salt and glucose are to be monitored in hypertensive and diabetic patients. Nutrients intake should be shifted from parenteral to per os as soon as the patient is able to sustain feeding. In re-initiating autonomous feeding, preference is given to liquid diets including milk, soups enriched with soja or ground meat.

Nursing care is of utmost importance for the prevention of bed sores that often results from hospital bed pressure. This is reduced through scheduled mobilization of the patient to release circulation and relieve pressure sites. The use of adequate mattresses and bed dressing may be helpful. Care also focuses on the liberation of airways as they are likely to obscure the prognosis. The detection and management of concurrent pathologies may improve the prognosis. This is especially the case for hypertension, diabetes, malaria, 
meningitis and other health conditions. Malaria may be diagnosed incidentally in standard blood smears that are effected for the confirmatory diagnosis of Loa loa infection. It may equally be purposefully sought when there are signs such as fever, omnibulation, diarrhoea or other signs suggestive of simple or cerebral malaria.

Practionners often recommend that corticoid should not be used as they may increase the risk of infection and/or gastrointestinal bleeding after prolonged use.

Because SAE is a medical emergency, all laboratory support tasks should be performed steadily and timely. These include tests for glycemia, blood smears, analyses of cerebrospinal fluid for Loa loa parasites and concurrent infection, such as meningitis.

\section{Operational consideration of Loa loa interventions in onchocerciasis control}

APOC, the leading organization in onchocerciasis control in Africa has led the development of tools for early detection and management of cases of SAE. Todate, mortality associated with the occurrence of encephalopathy is on the decline. As ivermectine is effective against both Onchocerca and Loa loa, the occurrence of ESG is proportional to the prevalence of high Loa loa microfilaremic individuals in affected communities. Thus, the probability of having cases decreases with the duration of effective mass treatment cycles (Figure 5).

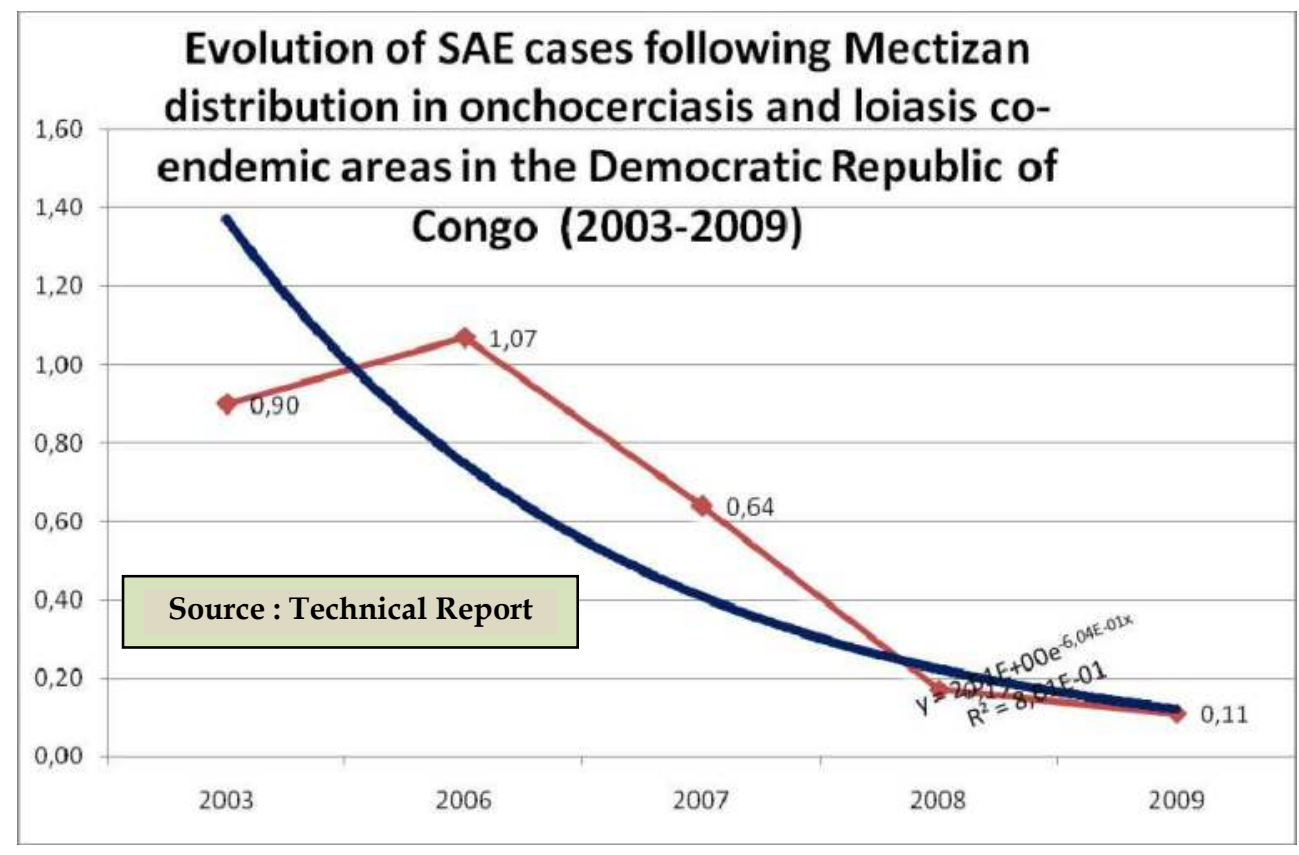

Fig. 5. Evolution of SAE cases following Ivermectine (Mectizan) distribution in onchocerciasis and loiasis co-endemic areas in the Democratic Republic of Congo(2003-2009) 
Even though the ESG represent a threat to CDTI operations, especially when encephalopathy triggered deaths are registered, it is still unethical to withhold treatment from thousands of people who live in oncherciasis and loiasis co-endemic areas. In that regard, special guidelines have been developed to inform mass distribution of ivermectine in such areas. Under such circumstances, operational teams are advised to avoid blanket treatment while giving precedence to focal, progressive treatment. The rate of expansion is then proportional to the number of expected cases of SAE, matched to the capacity of the local health infrastructure in available hospital beds, trained personnel and accessibility. Accessibility is a key determinant in countries where the road network is poor. Under some circumstances, mobile teams may be adopted or the capabilities of first line health facilities developed to permit the handling of severe illness resulting from SAE.

\section{Loa loa mediated encephalopathy and the future of neglected tropical diseases control}

Loiasis is a neglected disease that may have great social and economic impact in some endemic areas. Loiasis has for long been regarded as a benign filariasis. Its distribution that is limited to Central Africa has made it a less studied infection. The number of infected individuals was estimated at 2-13 millions (Fain, 1978). Interest in loiasis has been renewed as cases of encephalopathy occurred following treatment of onchocerciasis patients with high coincident Loa loa microfilareamia (Chippaux et al., 1996; Gardon et al., 1997; TwumDanso and Meredith, 2003). The occurrence of SAE affects compliance, treatment coverage and the sustainability of CDTI (Amazigo et al., 1998). Data on the distribution of Loa loa infection became mandatory to assess the risk of severe adverse events (SAE) as community directed treatment of onchocerciasis with ivermectin (CDTI) was extended to loiasis endemic areas. SAE are a constraint to community participation and compliance with CDTI. Working in Cameroon, the prevalence of Loa loa microfilareamia was found to reach rate of $31.5 \%$ in adults living in the dense forest area of Yokadouma (Languillon, 1957). Prevalences ranging from $9.6 \%$ to $13.5 \%$ were reported in the population of Colomines in the savannah area of the Kadei valley (Haumont et al., 1992). A model using satellite mapping of key environmental factors related to the biology of the Chrysops vector predicts a high prevalence of Loa loa at the regional level (Thomson et al., 2004), but the endemicity of loiasis at the community level may be unexpected (Kamgno and Boussinesq, 2001., Wanji et al., 2001). A study in eastern Cameroon indicated a high morbidity of the disease (Takougang et al., 2002). Loiasis was the second or third cause of medical consultations after malaria and pulmonary diseases in some endemic regions (Boulesteix and Carme, 1986; Pinder, 1988). Clinical manifestations of loasis in endemic areas have received little attention (Agbolade et al., 2005). The subconjunctival migration of adult worm, migratory angioedema and pruritus were the most reported signs (Carme et al, 1989; Noireau et al., 1990).

In most areas, the prevalence of eye worm and Calabar swellings were higher than that of microfilareamia. These observations denote that most clinical cases of Loa loa filariasis are amicrofilaraemic, and confirm previous observations (Touré et al., 1998; Touré et al., 1999, Pion et al., 2005). The prevalence of Loa loa infection that is estimated through the microscopic examination of standard blood film thus leads to an underestimation of the prevalence of loiasis. RAPLOA (Takougang et al., 2002), a tool based on the history of eye worm that is used for the rapid assessment of Loa loa infection, may provide a better 
estimate of the affliction. The term used for the identification of eye worm disease was consistent among the ethnic groups and languages. Most of the local names were composite, derived from the terms for "worm" and "eye". The widespread knowledge of signs and symptoms of Loa loa infection are an asset for community involvement in control, health education and promotion activities (Hewlett et al., 1996). The local names for Calabar swellings were less consistent than those of eye worm. Reports of Calabar swellings with intense itching corroborate previous findings (Morrone et al., 2002). The itching that is associated with Calabar swellings can be a cause of distraction from economic activities, and a source of social stigma and low self-esteem (Noireau, 1989). Subconjunctival migration of the worm causes considerable discomfort. It was associated with arthralgia and fatigue (Pinder, 1988; Morrone et al., 2002). These are constrains to productivity and economic development. The morbidity of eye worm disease may be heightened by the reported practices of traditional removal of the worm using a sharp blade, drops from the plants Allium cepa or Tithonia diversifolia, all of which may further damage the afflicted eye. The risk of physical and chemical damages to the eye consecutive to the local treatment practices, the secondary bacterial infections associated with local treatments may add on to the morbidity of loiasis in endemic populations. Loa loa related hypereosinophilia was suspected of playing a role in the aetiology of endocardial fibrosis (Pinder, 1988). In some case histories, glomerulonephritis, cardiomyopathy, retinopathy, lymphadenitis and lymphodoema were reported (Morrone et al., 2002; Agbodale et al., 2005). In a study carried out in Congo, headache and arthralgia were associated with Loa loa infection (Carme et al., 1989). The risk of SAE that has motivated most recent studies on Loa loa may therefore be a limited view of its health risks spectrum. There is an urgent need of interventions to prevent its health consequences. In that regard, albendazole may be a useful tool (Tabi et al., 2004). The mass distribution of ivermectin and albendazole within CDTI projects within the Global Programme to Eliminate Lymphatic Filariasis (GPELF) will have an incidental impact on Loa loa infection (Chippaux et al., 1998; Tsague-Dongmo, 2002).

Field observations have pointed out the effect of alcohol as a co-factor in the determination of ivermectin mediated SAE, but the information available is conflictive. Food and alcohol are known to alter ivermectin bio-availability (Baraka et al., 1996). The contra-indication of alcohol consumption around Ivermectine (Mectizan) intake as indicated by Merck \& Co., Inc. have safety concerns, but may unnecessarily deter some people from taking ivermectin (The Mectizan Expert Committee, 2000). Shu et al. (2000) failed to establish any enhanced occurrence of side effects in patients who consumed alcohol. .In a study carried out in Cameroon where some local beverages are produced from uncontrolled fermentation, with obviously higher alcohol content and diversity, Takougang et al. (2006) reported that the risk of SAE was higher when Ivermectine (Mectizan) was taken for the first time. Males were more likely than females to develop SAE. The occurrence of SAE was not associated with the timing of the last alcohol consumption, indicating that alcohol intake is not a major determinant of SAE. Because of the limited number of cases, the authors did not separate the different types of alcohols consumed. High content distilled alcohols may contribute to SAE, as these beverages contain a variety of alcohols which may be neurotoxic. Still the local palm and raphia wines, are blended with plant adjuvants, some of which may be potent neurotoxics. The plant Paullina pinnata (Salpindaceae) - locally called 'Mbami', 'Mbarbi' or 'lianes' - is known to cause head ache. The influence of these adjuvants as determinants of SAE deserves further investigations. 
It is possible that some participants (cases) could have denied alcohol consumption for fear of loosing the coverage of hospital costs as practiced by the National Onchocerciasis Control Programme.

One of the determinants of alcohol use and abuse contribution to ill health is the type of alcoholic beverage. Ethanol that is found in beverages may not be a key factor in SAE (Shu et al., 2000), but other alcohols such as methanol or buthanol of the locally produced "Arki", "Odontol" or "Hah" could contribute. The plant adjuvants of beverages may be at least cofactors. In one instance, a community distributor reported that a patient who developed SAE had ingested palm wine after ivermectin treatment. A similar case was quoted by Boussinesq et al. (2003). While there is an increased bioavailability of ivermectin following its co-administration with ethanol (Edwards et al., 1988; Cerkvenik and Grabnar, 2002), it is unlikely that the level of Ivermectin reached is high enough to cause SAE. The adjuvants of palm wine reported by Takougang et al., 2006 contain tannins, alkaloids and saponins which are all potent on the nervous system. Tannins increase capillary resistance, reduce capillary permeability of the red blood cells and are vasoconstrictors. Vasoconstriction of the extracranial arteries causes headache, restlessness and dizziness. Saponins are characterised by their tensio-active properties. Many saponins speed up haemoglobin degradation through their interaction with sterols of the membrane of the red blood cells. Alkaloids are complex nitrogenous substances with a bitter taste, that which is most preferred by consumers of palm wine. Alkaloids can be stimulants or depressors of the central nervous system (Bruneton, 1999). It is therefore required that the role of plant used as adjuvants in alcoholic drinks, as co-factors in SAE should be further assessed.

\section{Conclusion}

Early detection, operational adjustment and research based decision-making has contributed to improved management of SAE and encephalopathy in the control of onchocerciasis. However, further investigations are warranted on the sequelae and impact of encephalopathies on patient's productivity and quality of life. As the implementation of integrated control of Neglected Tropical Diseases progresses outside the onchocerciasis endemic areas, more challenges will be faced in lymphatic filariasis elimination areas. Implementation research will be needed to address operational issues, compliance, detection of novel side effects resulting from the co-administration of ivermectin, Albendazole and Praziquantel in previously naïve areas. Scaling up these interventions will equally face the genetic variability of human hosts and their cultural and behavioral correlates. Multidisciplinary collaborative research including epidemiology, social science, clinical and biological sciences will be warranted to address these issues.

\section{References}

Agbodale O.M., Akinboye D.O., Ogunkolo O.F. (2005). Loa loa and Mansonella perstans : Neglected human infections that need control in Nigeria. African Journal of Biotechnology, 4(13):1554-1558.

Amazigo U. 2008. APOC. Annals of Tropical Medicine and Parasitology 102(Suppl. 1): 19-22. Amazigo UV., Noma M., Boatin BA., Etya'ale DE., Seketeli A \& Dadzie KY. (1998). Delivery systems and cost recovery in Mectizan treatment for onchocerciasis. Annals of Tropical Medicine and Parasitology, 92(Suppl.1) :S23-S31. 
Amazigo UV, Obono OM, Dadzie KY, Remme J (2002). Monitoring community - directed treatment programmes for sustainability: lessons from the African programme for onchocerciasis control (APOC). Annals of Trop Med. Parasitol. 96 (1):575 - 592.

Baraka OZ, Mahmoud BM, Marschke CK, Geary TG, Homeida MM A, Williams JF (1996). Ivermectin distribution in the plasma and tissues of patients infected with Onchocerca volvulus. Eur. J. Clin. Pharmacol. 50:407-410.

Boulesteix G. \& Carme B. (1986). Encéphalite au cours du traitement de la filariose à Loa loa par la diéthylcarbamazin. A propos de 6 observations. Bulletin de la Société de Pathologie Exotique, 79 : 649-654.

Boussinesq M, Gardon J, Gardon-Wendel, N, Chippaux JP (2003). Clinical picture, epidemiology and outcome of Loa-associated serious adverse events related to mass ivermectin treatment of onchocerciasis in Cameroon. Filaria Journal 2:1-4.

Boussinesq M, Gardon J, Gardon J, Gardon-Wendel N, Kamgno J, Ngoumou P, Chippaux JP (1998). Three probable cases of Loa loa encephalopathy following ivermectin treatment for onchocerciasis. Am. J. Trop. Hyg. 58(4):461-469.

Boussinesq M., Gardon J., Kamgno J., Pion S.D., Gardon-Wendel N., Chippaux JP. (2001). Relationship between the prevalence and intensity of Loa loa in the Central Province of Cameroon. Annals of Tropical Medicine and Parasitology, 95(5):495-507.

Brieger W R. 2000. Implementation and sustainability of community-directed treatment of Onchocerciasis with ivermectin. Geneva, UNDP/World Bank/WHO Special Programme for Research and Training in Tropical Diseases.

Bruneton J (1999). Pharmacognosie. Phytochimie- Plantes Médicinales. Ed. Lavoisier., London.

Cerkvenik Flajs V, Grabnar I (2002). Ivermectin pharmacokinetics. Slov. Vet. Res. 39(3/4):167-178.

Carme B., Namboueni J.P., Copin N., Noireau F. (1989). Clinical and biological study of Loa loa filariasis in Congolese. American Journal of Tropical Medicine and Hygiene, 41(3):331-337.

Chippaux JP., Boussinesq M., Gardon J., Gardon-Wendel N. \& Ernould J-C. (1996). Severe adverse reaction risks during mass treatment with ivermectin in loiasis endemic areas. Parasitology Today, 12(11): 448-50.

Diggle P. J., Thomson M. C., Christensen O. F., Rowlingson B., Obsomer V., Gardon J., Wanji S., Takougang I., Enyong P., Kamgno J., Remme J. H, Boussinesq M.And Molyneux D. H. 2007. Spatial modelling and the prediction of Loa loa risk: decision making under uncertainty. Annals of Tropical Medicine \& Parasitology, Vol. 101, No. 6, 499-509

Duke BOL (2003). Overview: Report of a scientific working group on serious adverse events following Mectizan treatment of onchocerciasis in Loa loa endemic areas. Filaria Journal 2:1-4.

Edwards G, Dingsdale A, Helsby N, Orme ML, Breckenridge AM (1988). The relative systemic availability of ivermectin after administration as capsule, tablet, and oral solution. Eur. J. Clin. Pharmacol. 35:681-684.

Fain, A. (1978). Les problèmes actuels de la loase. Bulletin of the World Health Organization, 56:155-167. 
Gardon J, Gardon-Wendel N, Demanga-Ngangue, Kamgno J, Chippaux JP, Boussinesq M (1997). Serious reactions after mass treatment of onchocerciasis with ivermectin in an area endemic for Loa loa infection. The Lancet 3(50):18-22.

Gardon J., Gardon-Wendel N., Demanga-Ngangue, Kamgno J., Chippaux J.P., Boussinesq M. (1997). Serious reactions after mass treatment of onchocerciasis with ivermectin in an area endemic for Loa loa infection. Lancet; 350:18- 22.

Gish. O. 1992. Malaria Eradication and the Selective Approach to Health Care: Some Lessons from Ethiopia. International Journal of Health Services, 22(1): 179-192.

Hopkins A D. 2005. Ivermectin and Onchocerciasis : Is it all solved? Eye 19: 1057-1066.

Haumont G., Tribouley-Duret J., Villard H., Guy M., Lucchese F., Same Ekobo A. \& Ripert C. (1992). Etude épidémiologique des filarioses (onchocercose, loase, mansonellose) dans la vallée de la Kadéiii (Cameroun). Bulletin de Liaison et de Documentation de l'OCEAC, $99: 34-39$.

Hewlett B.S., Kollo B. \& Cline B.L. 1996. Ivermectin distribution and the cultural context of forest onchocerciasis in South Province, Cameroon. American Journal of Tropical Medicine and Hygiene, 54(5):517-522.

Kamgno J, Boussinesq M (2001). Hyperendémicité de la loase dans la plaine Tikar, région de savane arbustive du Cameroun. Bull. Soc. de Patho. Exot. 94(4):342-346.

Languillon J. (1957). Carte des filaires du Cameroun. Bulletin de la société de Pathologie Exotique, 50:417-427.

Morrone A., Franco G., Tchangmena O.B., Marangi M. (2002). A case of loiasis in Rome. Journal Européen de l'Académie de Dermatologie et de Vénérologie, 16(3):280-283.

National Institute of Neurological disorders and Stroke. NINDS Encephalopathy Information Page. Ninds.nih.gov/disorders/encephalopathy/encephalopathy.htm. Downloaded on 10 October 2011.

Noireau, F., Carme, B., Apembet, D. J. \& Gouteux, J. (1989). Loa and Mansonella filariasis in Chaillu mountains, Congo: parasitological prevalence. Transactions of the Royal Society of Tropical Medicine and Hygiene, 83, 529-534.

Pinder M. (1988). Loa loa - A Neglected Filaria. Parasitology Today, 4(10):279-284.

Pion S.D.S., Demanou M., Oudin B., Boussinesq M. (2005). Loiasis: the individual factors associated with the presence of microfilareamia. Annals of Tropical Medicine and Parasitology, 99(5):491-500.

Richards F O., Boatin B., Sauerbrey M., Seketeli A. 2004. Control of Onchocerciasis_Today: Status and challenges. Trends in Parasitology 17: 558-563.

Shu EN, Onwujekwe EO, Okonkwo PO (2000). Do alcoholic beverages enhance availability of ivermectin? Eur. J. Clin. Pharmacol. 56:437-438.

Tabi E.T., Befidi-Mengue R., Nutman T.B., Horton J., Folefalk A., Pensia E., Fualem R., Fogako J., Gwanmesia P., Quakyi I., Leke R. (2004). Human loiasis in a Cameroonian village: A double-blind, placebo controlled, crossover clinical trial of a three-day albendazole regimen. American Journal of Tropical Medicine and Hygiene, 71(2):211-215.

Takougang I., Meremikwu M., Wanji S., Yenshu E.V., Aripko B., Lamlenn S.B., Eka I.B., Enyong P., Meli J., Kale O., Remme J.H. (2002). A rapid assessment method for Loa loa endemicity. Bulletin of the World Health Organization, 80(11):852-858. 
Takougang I, Meli J, Lamlenn S, Tatah Pn \& Ntep M. 2007. Loiasis, a Neglected and Underestimated Affliction: Endemicity, Morbidity and Perceptions in Eastern Cameroon. Annals of Tropical Medicine and Parasitology. 101(2):151-160.

The Mectizan Expert Committee. 2000. Recommendations for the treatment of onchocerciasis with Mectizan in areas co-endemic for onchocerciasis and loiasis.

Thomson M.C., Obsomer V., Kamgno J., Gardon J, Wanji S., Takougang I, Enyong P., Remme J.H., Molyneux D.H. \& Boussinesq M. (2004). Mapping the distribution of Loa loa in Cameroon in support of the African Programme for Onchocerciasis Control.Filaria Journal, 3:7

Touré F.S., Deloron P., Egwang T. G., Wahl G. (1999). Relation entre intensité de la transmission de la filaire Loa loa et prévalence des infections. Médecine Tropicale, 59(3): $249-252$.

Touré F.S., Mavoungou E., Kassambara L., Williams T., Wahl G.M., Egwang T.G. (1998).Human occult loiasis: field evaluation of a nested polymerase chain reaction assay for the detection of occult infection. Tropical Medicine and International Health, 3(6): $505-511$.

Tsague-Dongmo L., Kamgno J., Pion SD., Moyou-Somo R., Boussinesq M. (2002). Effects of a 3-day regimen of albendazole (800 $\mathrm{mg}$ daily) on Loa loa microfilareamia. Annals of Tropical Medicine and Parasitolology, 96(7):707-715.

Twum-Danso NAY, Meredith SEO (2003). Variation in incidence of serious adverse events after onchocerciasis treatment with ivermectin in areas of Cameroon co-endemic for loiasis. Trop. Med. and Internat. Health. 8(9):820-831.

WHO (1992). The Alcohol Use Disorders Identification Test: Guidelines for use in Primary Healthcare. Programme on Substance Abuse. World health Organization. WHO/PSA/92.4.

WHO (1995). Onchocerciasis and its control. Report of a WHO Expert Committee on Onchocerciasis Control. WHO Tech. Rep. Ser. N852. Geneva.

WHO 2006. Report -working together for health. Geneva.

WHO. 2008. Primary Health Care - Now More than Ever. Geneva. 


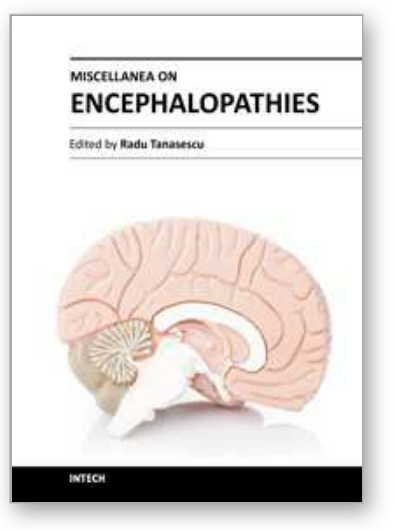

\author{
Miscellanea on Encephalopathies \\ Edited by Dr. Radu Tanasescu
}

ISBN 978-953-51-0499-5

Hard cover, 202 pages

Publisher InTech

Published online 18, April, 2012

Published in print edition April, 2012

The book project "Miscellanea on Encephalopathies" aims to cover some of the important aspects of infectious-related encephalopathies, post-transplantation and drug-induced encephalopathies, by transmitting valuable information filtered through the real life clinical and research experience of the authors.

\title{
How to reference
}

In order to correctly reference this scholarly work, feel free to copy and paste the following:

Takougang Innocent and Muteba Daniel (2012). Encephalopathy Related to Ivermectin Treatment of Onchocerciasis in Loa loa Endemic Areas: Operational Considerations, Miscellanea on Encephalopathies, Dr. Radu Tanasescu (Ed.), ISBN: 978-953-51-0499-5, InTech, Available from:

http://www.intechopen.com/books/miscellanea-on-encephalopathies/encephalopathies-in-onchocerciasiscontrol-etiology-impact-and-prevention

\section{INTECH}

open science | open minds

\author{
InTech Europe \\ University Campus STeP Ri \\ Slavka Krautzeka 83/A \\ 51000 Rijeka, Croatia \\ Phone: +385 (51) 770447 \\ Fax: +385 (51) 686166 \\ www.intechopen.com
}

\author{
InTech China \\ Unit 405, Office Block, Hotel Equatorial Shanghai \\ No.65, Yan An Road (West), Shanghai, 200040, China \\ 中国上海市延安西路65号上海国际贵都大饭店办公楼 405 单元 \\ Phone: +86-21-62489820 \\ Fax: $+86-21-62489821$
}


(C) 2012 The Author(s). Licensee IntechOpen. This is an open access article distributed under the terms of the Creative Commons Attribution 3.0 License, which permits unrestricted use, distribution, and reproduction in any medium, provided the original work is properly cited. 